DOI: $10.12731 / 2070-7568-2020-1-159-172$

УДК 378:332

\title{
ВЕКТОР РАЗВИТИЯ ФГБОУ ВО «КАЗАНСКАЯ ГОСУДАРСТВЕННАЯ АКАДЕМИЯ ВЕТЕРИНАРНОЙ МЕДИЦИНЫ ИМЕНИ Н.Э. БАУМАНА»
}

Морозова И.Г., Зарипова Р.С.

Современные экономические условия требуют подготовки высококвалифицированных специалистов. Повышение качества высшего профессионального образования в настоящее время является одной из актуальных проблем не только для России, но для всего мирового сообщества. Решение этой проблемы связано с модернизащией образования, оптимизацией способов и технологий организации образовательного прочесса.

Предметной областью исследования в данной статье является образовательная организация и ее место в региональном пространстве. В рамках проведенного исследования авторами была изучена деятельность ФГБОУ ВО «Казанская государственная академия ветеринарной медицины им. Н.Э. Баумана» (КГАВМ), проведён комплексный анализ функционирования и выделены сильные и слабые стороны работы КГАВМ. В результате исследований была выявлена необходимость в практико-ориентированном подходе обучения и усилении хозяйственной деятельности ВУЗа. Устранение данных недостатков позволят студентам КГАВМ приобрести необходимый минимум профессиональных умений и навыков, опыт организаторской работы, систему теоретических знаний, профессиональную мобильность и компетентность, что соответствует образовательному стандарту и, следовательно, сделает выпускников конкурентоспособными.

Цель работы: изучить деятельность КГАВМ, провести комплексный анализ функиионирования, выделить сильные и слабые стороны работы ВУЗа, определить основные направления и барьеры развития КГАВМ. 
Методология проведения работы: системный подход и обобщение; собственный научно-педагогический опыт авторов; аналитические и статистические методы анализа, социологические опросы и анкетирование.

Результаты: получены информативныле параметры, показывающие слабые и сильные стороны деятельности КГАВМ.

Область применения результатов: полученные результаты целесообразно применять образовательными организациями.

Ключевые слова: высшее образование; образовательная организация; кластеризация; кадровый потенциал; стратегическое развитие.

\section{VECTOR OF ECONOMIC DEVELOPMENT OF FSBEI «KAZAN STATE ACADEMY OF VETERINARY MEDICINE NAMED AFTER N.E. BAUMAN»}

Morozova I.G., Zaripova R.S.

Modern economic conditions require the training of highly qualified specialists. Improving the quality of higher professional education is currently one of the urgent problems not only for Russia, but for the entire world community. The solution of this problem is connected with modernization of education, optimization of methods and technologies of educational process organization.

The subject area of research in this article is educational organization and its place in the regional space. Within the framework of the research the authors have studied the activity of "Kazan State Academy of Veterinary Medicine named after N.E. Bauman”. A comprehensive analysis of the functioning of the university was carried out and the strengths and weaknesses of the university were highlighted. As a result of researches necessity in the practice-oriented approach of training and strengthening of economic activity of the university has been revealed. Elimination of these disadvantages will allow the students of KSAVM to acquire the necessary minimum of professional skills, experience in 
organizational work, the system of theoretical knowledge, professional mobility and competence, which corresponds to the educational standard and, therefore, will make the graduates competitive.

Purpose: to determine the main directions and barriers of KSAVM development.

Methodology of the work: systematic approach and generalization; authors'own scientific and pedagogical experience; analytical and statistical methods of analysis, sociological surveys and student questionnaires.

Results: The most informative parameters showing the weaknesses and strengths of KSAMC's activity were obtained.

The score of the results: the received results should be used by educational organizations.

Keywords: higher education; educational organization; clusterization; human resources potential; strategic development.

\section{Введение}

Федеральное государственное бюджетное образовательное учреждение высшего образования «Казанская государственная академия ветеринарной медицины им. Н.Э. Баумана» является правопреемником Казанского ветеринарного института имени Н.Э. Баумана, который был образован 31 мая 1873 года. В 1986 г. институт переименован в Казанскую государственную академию ветеринарной медицины имени Н.Э. Баумана. Академия является старейшим учебным заведением ветеринарного профиля в России. За годы существования академией подготовлено более 22 тысяч ветеринарных врачей и зооинженеров. В настоящее время в составе академии 3 факультета, 28 кафедр, учебно-опытное хозяйство, административно-хозяйственные, социально-бытовые, спортивные и другие подразделения. Подготовка специалистов в академии ведется по трем специальностям и шести специализациям.

Академия располагает квалифицированным профессорско-преподавательским составом, обеспечивающим подготовку специалистов в соответствии с требованиями профессиональных образовательных программ. Численность профессорско-преподавательского состава 
составляет 219 человек, из которых 156 (71,2\%) имеют ученые звания и степени, в том числе 40 (25,6\%) доктора наук, профессора. Ученые степени и звания сотрудников подтверждаются ежегодными научными исследованиями и соответствующими публикациями. Издаются как научные статьи, так и учебно-методические пособия для обеспечения образовательного процесса. Так в 2018 году сотрудниками Академии ветеринарной медицины было опубликовано 34 учебных пособия, 16 монографий и 11 учебников, в то время как в прошлом году данные показатели составили все 4 учебных пособия и 3 монографии.

Целью работы является изучение деятельности КГАВМ, проведение комплексного анализа его функционирования, выявление сильных и слабых сторон работы ВУЗа, определение основных направлений и барьеров развития КГАВМ. В ходе проведенного обзора и анализа иностранной и отечественной литературы было установлено, что в литературных источниках нет решения данной проблемы.

\section{Материалы и методы}

Системный подход и обобщение; собственный научно-педагогический опыт авторов; аналитические и статистические методы анализа, социологические опросы и анкетирование.

\section{Результаты}

Проведенный анализ деятельности КГАВМ показал следующие результаты.

Ежегодно ВУЗ выпускает более ста дипломированных специалистов, большая часть которых трудоустраивается (табл. 1). Если в 2017 году наблюдался незначительный спад количества выпущенных специалистов, то в 2018 году показатели превзошли уровень 2016 года. Доля трудоустроенных специалистов колеблется на отметке 65-70\% от выпуска.

Помимо подготовки студентов по программам бакалавриата и магистратуры в КГАВМ осуществляется выпуск и по программам аспирантуры. Подготовка аспирантов происходит по двум направлениям подготовки: 06.06.01 - биологические науки; 36.06.01 - ветеринария и зоотехния. Численность аспирантов, обучающихся на бюджетной 
основе, ежегодно составляет более 40 человек, при этом договорная основа становится все менее привлекательной для студентов. Если в 2016 году на договорной основе по направлению обучалось 14 аспирантов, то в 2018 году данный показатель составил всего 4 человека.

Таблийа 1.

Динамика выпущенных и трудоустроенных студентов

\begin{tabular}{|c|c|c|c|c|c|c|c|}
\hline \multirow[b]{3}{*}{ Специальности } & \multirow[b]{3}{*}{$\begin{array}{l}\text { Ед. } \\
\text { изм. }\end{array}$} & \multicolumn{6}{|c|}{ Годы } \\
\hline & & \multicolumn{2}{|c|}{2018} & \multicolumn{2}{|c|}{2017} & \multicolumn{2}{|c|}{2016} \\
\hline & & $\begin{array}{ll} & \\
& 0 \\
& 0 \\
0 \\
0\end{array}$ & 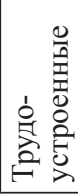 & 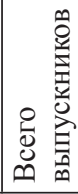 & 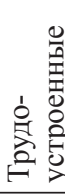 & 总 & 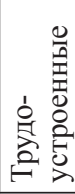 \\
\hline 35.05 .01 «Ветеринария» & \multirow{4}{*}{ чел. } & 117 & 87 & 107 & 69 & 115 & 75 \\
\hline $\begin{array}{l}36.03 .01 \text { «Ветеренарно-санитарная } \\
\text { экспертиза» }\end{array}$ & & 18 & 9 & 16 & 13 & 20 & 17 \\
\hline 36.03 .02 «Зоотехния» & & 25 & 18 & 20 & 13 & 21 & 9 \\
\hline Всего: & & 160 & 114 & 143 & 95 & 156 & 101 \\
\hline
\end{tabular}

Следует отметить численность иностранных студентов академии из стран дальнего и ближнего зарубежья, таких как Вьетнам, Израиль, Королевство Марокко и т.д., которая существенно выросла по сравнению с 2016 годом. Если в 2016 году число иностранных студентов составляло 93 человека, то в 2018 году данный показатель вырос до 144 человек, темп прироста составил 54,8\%.

Мониторинг цен за обучение во внебюджетных группах на базе первого курса очного отделения по трем специальностям: зоотехния, ветеринария, ветеринарно-санитарная экспертиза в 2018 году позволяет сделать вывод о высоком уровне цен за обучение в Академии ветеринарной медицины (табл. 2).

Согласно результатам таблицы 2, цены за обучение в Казанской государственной академии ветеринарной медицины уступают Московской государственной академии ветеринарной медицины и биотехнологии им. К.И. Скрябина. Аграрные университеты иллюстрируют более низкий уровень цен, отвлекая тем самым внимание студентов на себя. 
Таблицุа 2.

Мониторинг цен за обучение, тыс. руб.

\begin{tabular}{|l|c|c|c|c|c|}
\hline \multicolumn{1}{|c|}{$\begin{array}{c}\text { Наименование } \\
\text { специальности }\end{array}$} & МГАВМиБ & СГАУ & БГАУ & КГАУ & КГАВМ \\
\hline Зоотехния & 245000 & 109100 & 127400 & 92400 & 131808 \\
\hline Ветеринария & 245000 & 109100 & 127240 & 92400 & 131808 \\
\hline $\begin{array}{l}\text { Ветеринарно-санитарная } \\
\text { экспертиза }\end{array}$ & 245000 & 116800 & - & - & 131808 \\
\hline
\end{tabular}

Для рассмотрения преимуществ и недостатков обучения в КГАВМ было проведено анонимное анкетирование студентов 2 и 3 курсов. По итогам опроса было выявлено, что большая часть респондентов узнала о существовании ВУЗа из Интернет и СМИисточников (рис. 1).

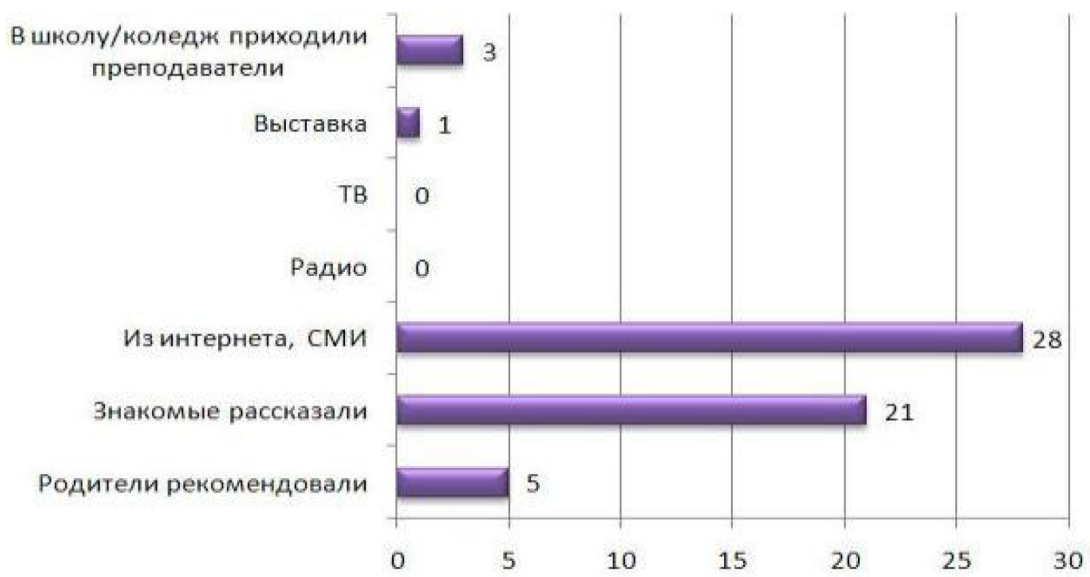

Рис. 1. Ответ на вопрос «Из каких источников Вы узнали о КГАВМ?»

Согласно поведенному опросу было выявлено, что основной причиной выбора КГАВМ стала любовь к животным, при этом 11 человек студентов считают ветеринарию своим призванием (рис. 2).

Основные критерии престижности ВУЗа (рис. 3) согласно мнению респондентов складывается из следующих составляющих:

- успешное трудоустройство по окончанию ВУЗа;

- наличие диплома государственного образца;

- наличие бюджетных мест. 


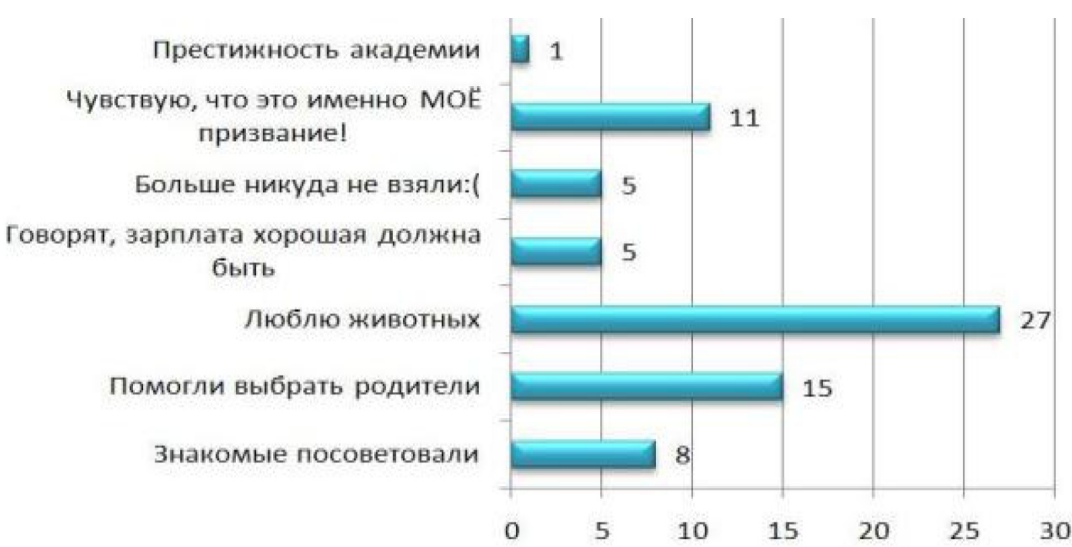

Рис. 2. Ответ на вопрос «Причина выбора КГАВМ в качестве места обучения?»

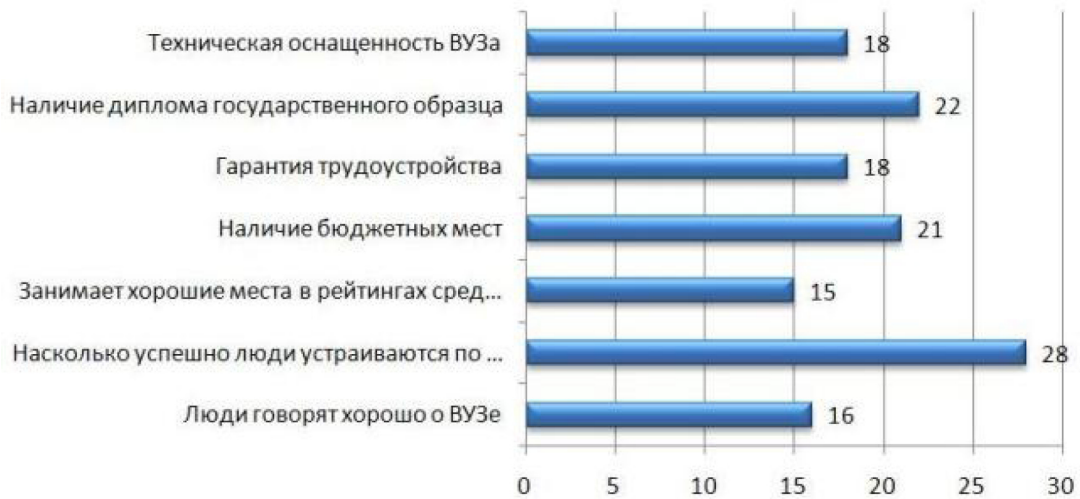

Рис. 3. Критерии, характеризующие престижность ВУЗа, согласно опросу

В результате опроса студентов также были выявлены недостатки ВУЗа (рис. 4).

Согласно результатам данного опроса, главным недостатком ВУЗа является слабый практико-ориентированный подход в обучении студентов. Суть практико-ориентированного обучения - это освоение студентами образовательной программы не в аудитории, а в реальном деле, формирование у студентов профессиональных компетенций за счет выполнения ими реальных практических задач в учебное время в ведущих профильных организациях. 


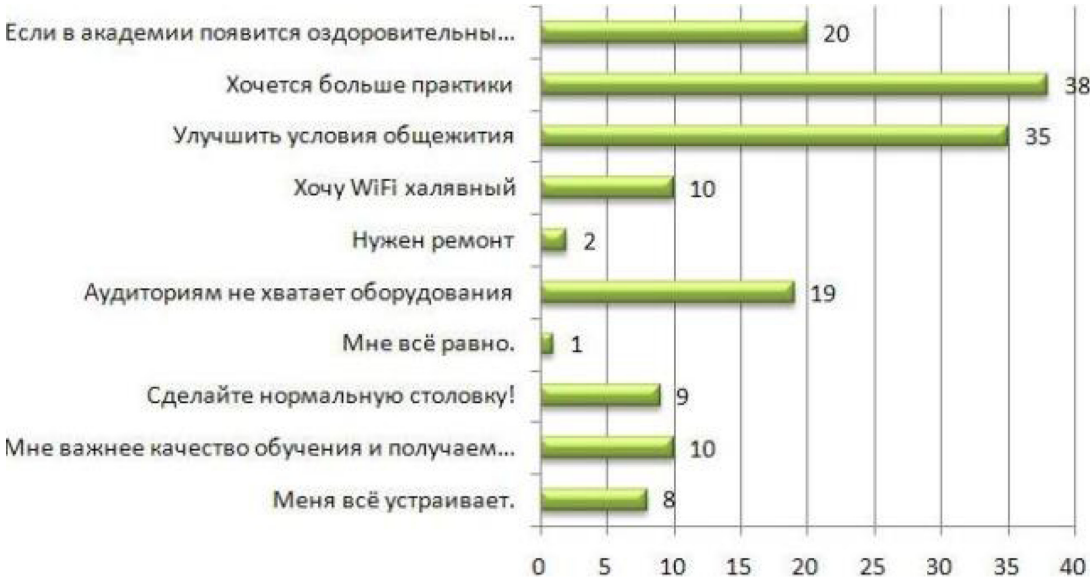

Рис. 4. Ответ на вопрос «Какие недостатки ВУЗа Вы могли бы выделить?»

Среди всех выявленных слабых сторон недостаток практики является наиболее весомым, в связи с чем развитие собственной ветеринарной клиники становится ключевым вопросом развития ВУЗа. Мониторинг ветеринарных клиник по районам г. Казани показал, что в Авиастроительном, Вахитовском и Московском районах города Казани крайне малое количество ветеринарных клиник (табл. 3). Таким образом, открытие клиник при ВУЗе в данных районах города Казани сможет решить вопрос создания дополнительной базы практики для студентов.

Таблицุа 3.

Мониторинг ветеринарных клиник в г. Казань

\begin{tabular}{|l|c|c|}
\hline $\begin{array}{c}\text { Наименование } \\
\text { района }\end{array}$ & $\begin{array}{c}\text { Ед. } \\
\text { изм. }\end{array}$ & $\begin{array}{c}\text { Количество } \\
\text { ветеринарных } \\
\text { клиник }\end{array}$ \\
\hline Авиастроительный & & 6 \\
\cline { 1 - 1 } Вахитовский & \multirow{4}{*}{ шт. } & 8 \\
\cline { 1 - 1 } Кировский & 10 \\
\cline { 1 - 1 } Московский & 8 \\
\hline Ново-Савиновский & 14 \\
\cline { 1 - 1 } Приволжский & 14 \\
\cline { 1 - 1 } Советский & 36 \\
\hline
\end{tabular}


Студенты также желали бы улучшить условия проживания в общежитии. Кроме того, студентам не хватает возможности посещения оздоровительного комплекса. Остро стоит вопрос об оснащенности аудиторий и наличии интернета $[12,15]$. Как следует из статьи [9] в настоящее время интернет является необходимым и обязательным условием для обучения.

Другим направлениями развития экономической деятельности КГАВМ могут стать внедрение системы среднего профессионального образования на базе колледжа. Как следует из статьи [10], система среднего профессионального образования в настоящее время набирает все большую популярность. Число студентов колледжей и техникумов неуклонно растет. Процессу роста численности студентов, обучающихся по программам среднего профессионального образования, способствует активное развитие движения WorldSkills Russia, главной целью которого является повышение престижа рабочих профессий и развитие профессионального образования посредством объединения лучших практик и профессиональных стандартов с привлечением к работе квалифицированных специалистов, способных передать накопленный опыт новому поколению молодых профессионалов [14]. Как следует из статьи [6], «Ветеринария» является одной из компетенций чемпионата WorldSkills. Конкурсное задание складывается из нескольких независимых модулей, в ходе реализации которых подвергаются проверке следующие области знаний: микробиология, эпизоотология, оперативная хирургия, клиническая диагностика, акушерство, ветеринарно-санитарная экспертиза. Реализация данной компетенции в рамках чемпионата ориентирует педагогов на высокий уровень подготовки студентов, а также повышает привлекательность профессии для молодых людей, желающих обучаться по программам среднего профессионального образования.

Преимуществом КГАВМ является наличие структурированности образования. После получения степени бакалавра можно продолжить обучение в магистратуре и далее в аспирантуре, не покидая любимый ВУЗ [13]. 
Еще одним необходимым направлением развития ВУЗа становится развитие службы маркетинга $[1-4,11]$. Позиционирование высшего учебного заведения на рынке образовательных услуг становится насущной необходимостью в современной экономической системе [5, $7,8]$. Проведение маркетинговых исследований в области изучения и анализа абитуриентов, возможных направлений подготовки, спектра оказываемых услуг на базе ветеринарной клиники, а также логотипа ВУЗа смогло бы выявить имеющиеся недостатки с целью их дальнейшей проработки. Учитывая расширяющиеся возможности привлечения студентов с удаленных территорий страны, в настоящее время необходимо серьезно подойти к вопросам формирования узнаваемости ВУЗа.

\section{Заключение}

В результате проведенного анализа деятельности ФГБОУ ВО «Казанская государственная академия ветеринарной медицины имени Н.Э. Баумана» были выявлены сильные и слабые стороны обучения, которые выглядят следующим образом (табл. 4).

Таблицуа 4.

\section{Сильные и слабые стороны организации}

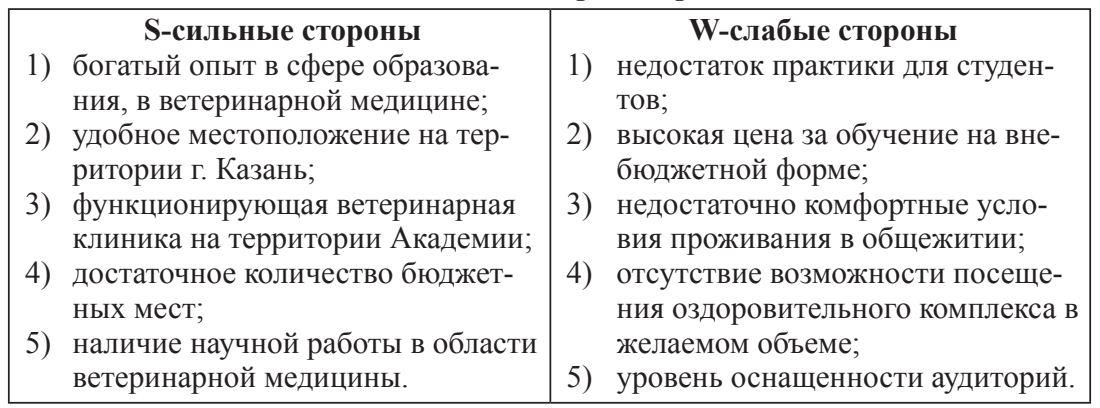

Таким образом, очевидна необходимость в практико-ориентированном подходе обучения студентов, ребрендинга ВУЗа и усиление деятельности в хозяйственной части, в частности улучшение условий проживаний в общежитии, обеспечение студентов интернетом в кампусе ВУЗа, повысить уровень оснащенности аудиторий современным оборудованием и техникой. Устранение данных недостатков позволит увели- 
чит привлекательность данного ВУЗа для абитуриентов, повысить его рейтинг, а также позволит студентам КГАВМ приобрести необходимый минимум профессиональных умений и навыков, опыт организаторской работы, систему теоретических знаний, профессиональную мобильность и компетентность, что соответствует образовательному стандарту и, следовательно, сделает выпускников конкурентоспособными.

\section{Список литературы}

1. Баталова О.С. Специфика образовательной услуги как основа маркетинговой политики вуза // Актуальные вопросы экономики и управления: Материалы Международной заочной научной конференции. М.: РИОР, 2011. С. 7-12.

2. Белый Е.М. Обеспечение рыночной устойчивости высших учебных заведений // Современные проблемы науки и образования. 2012. № 2. С. 334.

3. Бок. Д. Университеты в условиях рынка. Коммерциализация высшего образования. М.: Изд. Дом Высшей школы экономики. 2012. 224 с.

4. Волкова М.М., Звездова А.Б. Маркетинговые исследования в области образовательных услуг // Маркетинг. 1999. № 6. С. 3.

5. Зарипова Р.С., Пырнова О.А. Управление деятельностью организаций в условиях цифровой экономики // Ученые записки ИСГЗ. 2018. T.16. №2. С. 70-75.

6. Кузина Т.А. Чемпионат «Молодые Профессионалы» как инструмент развития профессиональных навыков участников в компетенции «Ветеринария» // Образование. Карьера. Общество. 2019. №1 (60). С. 52-53.

7. Новикова Н.Г., Мухоморова И.В. Проблемы формирования и реализации государственной политики в сфере высшего профессионального образования и пути их решения // Вестник Ассоциации вузов туризма и сервиса. 2013. № 1. С. 62-66.

8. Новикова Н.Г., Мухоморова И.В. Развитие высшего образования в условиях современной экономики // Сервис в России и за рубежом. 2014. T.8. №9 (56). С. 81-88.

9. Пырнова О.А., Зарипова Р.С. Интернет как средство обучения // International Journal of Advanced Studies in Education and Sociology. 2018. №2. C. 41-44. 
10. Чернышева Е.И., Позднякова Т.В. К вопросу об оценке профессиональных компетенций у студентов техникума специальности «Ветеринария» // Перспективы науки и образования. 2017. №. 5 (29). С. 29-33.

11. Шакиров А.А., Зарипова Р.С. Проблема разработки и реализации стратегии в российских компаниях при переходе к цифровой экономике // Наука Красноярья. 2019. Т. 8. № 3-3. С. 101-105.

12. Banek Zorica M., Špiranec S., Buselic V. Information Literacy: Key to an Inclusive Society. 4th European Conference. ECIL 2016. Prague. Czech Republic. 2016. Revised Selected Papers, pp. 99-108.

13. Pathmaloshini N. The implications of structuration theory for education. Masters Degrees (Education, Development, Leadership and Management). http://hdl.handle.net/10413/3485.

14. Sin C., Amaral A. Academics' and employers' perceptions about responsibilities for employability and their initiatives towards its development. Higher Education. 73 (1). 2017, pp. 97-111.

15. Welsh R.O. Opposite Sides of the Same Coin? Exploring the Connections between School Absenteeism and Student Mobility. Journal of Education for students placed at risk. V. 23. 2018, pp. 70-92.

\section{References}

1. Batalova O.S. Specifika obrazovatel'noj uslugi kak osnova marketingovoj politiki vuza [Specificity of educational service as a basis of marketing policy of university]. Aktual'nye voprosy ekonomiki i upravleniya: Materialy Mezhdunarodnoj zaochnoj nauchnoj konferencii [Actual problems of economics and management: Materials of the International Correspondence Scientific Conference]. M.: RIOR, 2011, pp.7-12.

2. Belyj E.M. Obespechenie rynochnoj ustojchivosti vysshih uchebnyh zavedenij [Ensuring Market Stability of Higher Education Institutions]. Sovremennye problemy nauki i obrazovaniya. 2012. № 2. pp. 334.

3. Bok. D. Universitety v usloviyah rynka. Kommercializaciya vysshego obrazovaniya [Universities in market conditions. Commercialization of higher education]. M.: Izd. Dom Vysshej shkoly ekonomiki. 2012. 224 p.

4. Volkova M.M., Zvezdova A.B. Marketingovye issledovaniya v oblasti obrazovatel'nyh uslug [Marketing research in the field of educational services]. Marketing. 1999. № 6, p. 3. 
5. Zaripova R.S., Pyrnova O.A. Upravlenie deyatel'nost'yu organizacij v usloviyah cifrovoj ekonomiki [Management of the organizations activity in the digital economy conditions]. Uchenye zapiski ISGZ. 2018. V.16. №2, pp. 70-75.

6. Kuzina T.A. Chempionat "Molodye Professionaly" kak instrument razvitiya professional'nyh navykov uchastnikov v kompetencii "Veterinariya" [Young Professionals" as a tool of development of professional skills of participants in competence "Veterinary"]. Obrazovanie. Kar'era. Obshchestvo. 2019. №1(60), pp. 52-53.

7. Novikova N.G., Muhomorova I.V. Problemy formirovaniya i realizacii gosudarstvennoj politiki v sfere vysshego professional'nogo obrazovaniya i puti ih resheniya [Problems of formation and realization of the state policy in the field of higher professional education and ways of their solution]. Vestnik Associacii vuzov turizma i servisa. 2013. № 1, pp. 62-66.

8. Novikova N.G., Muhomorova I.V. Razvitie vysshego obrazovaniya v usloviyah sovremennoj ekonomiki [Development of higher education in the modern economy]. Servis v Rossii i za rubezhom. 2014. V.8. №9 (56). pp. 81-88.

9. Pyrnova O.A., Zaripova R.S. Internet kak sredstvo obucheniya [Internet as a means of training]. International Journal of Advanced Studies in Education and Sociology. 2018. № 2, pp. 41-44.

10. Chernysheva E.I., Pozdnyakova T.V. K voprosu ob ocenke professional'nyh kompetencij u studentov tekhnikuma special'nosti «Veterinariya» [To the question about the professional competence estimation at the students of technical school of "Veterinary science" specialty]. Perspektivy nauki i obrazovaniya. 2017. №. 5 (29), pp. 29-33.

11. Shakirov A.A., Zaripova R.S. Problema razrabotki i realizacii strategii $\mathrm{v}$ rossijskih kompaniyah pri perekhode k cifrovoj ekonomike [Problem of strategy development and implementation in the Russian companies in the transition to the digital economy]. Nauka Krasnoyar 'ya. 2019. V. 8. № 3-3, pp. 101-105.

12. Banek Zorica M., Špiranec S., Buselic V. Information Literacy: Key to an Inclusive Society. 4th European Conference. ECIL 2016. Prague. Czech Republic. 2016. Revised Selected Papers, pp. 99-108.

13. Pathmaloshini N. The implications of structuration theory for education. Masters Degrees (Education, Development, Leadership and Management). http://hdl.handle.net/10413/3485. 
14. Sin C., Amaral A. Academics' and employers' perceptions about responsibilities for employability and their initiatives towards its development. Higher Education. 73 (1). 2017, pp. 97-111.

15. Welsh R.O. Opposite Sides of the Same Coin? Exploring the Connections between School Absenteeism and Student Mobility. Journal of Education for students placed at risk. V.23. 2018, pp. 70-92.

\section{ДАННЫЕ ОБ АВТОРАХ}

Морозова Ирина Геннадиевна, доцент кафедры «Маркетинг и экономика», кандидат экономических наук

Казанский инновационный университет им. В.Г. Тимирясова ул. Московская, 42, г. Казань, Респ. Татарстан, 420111, Российская Федерация igmorozova@ieml.ru

Зарипова Римма Солтановна, доцент, кандидат технических наук Казанский государственный энергетический университет ул. Красносельская, 51, г. Казань, Татарстан, 420066, Российская Федерация zarim@rambler.ru

\section{DATA ABOUT THE AUTHORS}

Morozova Irina Gennadievna, Associate Professor «Marketing and Economics», Candidate of Economic Sciences Kazan Innovative University named after V.G. Timiruasov 42, Moscovskaya St., Kazan, Republic of Tatarstan, 420111, Russian Federation igmorozova@ieml.ru

Zaripova Rimma Soltanovna, associate Professor, candidate of technical Sciences

Kazan State Power Engineering University

51, Krasnoselskaya St., Kazan, Republic of Tatarstan, 420066, Russian Federation zarim@rambler.ru 